\title{
ÉPOCA E HORÁRIO DE APLICAÇÃO DE FUNGICIDA SOBRE A QUALIDADE DE SEMENTES DE ARROZ ${ }^{1}$
}

\author{
MARCUS DAVI FERREIRA TEPLIZKY ${ }^{2}$, LUIS OSMAR BRAGA SCHUCH ${ }^{3}$, \\ ADEMIR DOS SANTOS AMARAL ${ }^{4}$, FERNANDO AUGUSTO HENNING ${ }^{2}$
}

\begin{abstract}
RESUMO - Objetivou-se neste trabalho avaliar os efeitos da época e do horário de aplicação de fungicida sobre o rendimento e a qualidade de sementes de arroz irrigado. $\mathrm{O}$ experimento foi conduzido no município de Pelotas-RS, na safra 2005/2006. Utilizou-se a cultivar "Combat" e o fungicida Folicur $200 \mathrm{CE} \square$ (tebuconazole $200 \mathrm{~g} / \mathrm{L}$ ), na dosagem de $0,5 \mathrm{~L} /$ ha do produto comercial. Testou-se uma combinação fatorial $(3 \times 3+1)$, com aplicação do fungicida em três estádios de floração $(5 \%, 50 \%$ e 80\%) e em três horários de aplicação ( 9 horas, 13 horas e 17 horas), e um tratamento adicional sem fungicida (testemunha). Após a colheita das sementes, avaliou-se a qualidade fisiológica pelos testes de germinação e vigor (primeira contagem da germinação, teste de frio e emergência em solo). Adicionalmente foram avaliados a porcentagem de esterilidade, o peso de mil sementes, o rendimento e a sanidade das sementes. De acordo com os resultados deste trabalho, a aplicação de fungicida na cultura do arroz, resulta em maior rendimento e melhor qualidade de sementes, independente do horário e da época de aplicação do produto. A aplicação de fungicida às 13 horas apresenta menor rendimento em relação aos demais horários de aplicação. Em horário com temperaturas elevadas e em estádios de floração mais avançados, a aplicação de fungicida resulta em sementes de menor qualidade.
\end{abstract}

Termos para indexação: Oryza sativa, sanidade, esterilidade, vigor.

\section{SPRAY SCHEDULE AND TIMING OF FUNGICIDE APPLICATION ON IRRIGATED RICE SEED QUALITY}

\begin{abstract}
The aim in this was to evaluate the effect off the spray temming and time (hour of the day) of fungicide aplication, during the flowering period on the physiological seed quality, seed health, sterility, weight of thousand seeds and yield of irrigated rice. The experiment was conducted in Pelotas, RS, during the 2005/06 growing season when the "Combat" cultivar was sprayed with Folicur $200 \mathrm{CE}$ (tebuconazol $200 \mathrm{~g} / \mathrm{L}$ ), at the rate of $0.5 \mathrm{~L} \mathrm{commercial} \mathrm{product/ha.}$ The experimental design was a factorial combination $(3 \times 3+1)$ of fungicide application at three flowering stages $(5 \%, 50 \%$ and $80 \%$ ) and three timings ( 9 am, $1 \mathrm{pm}$ and $5 \mathrm{pm}$ ). After harvesting, the seed physiological quality was evaluated by the germination and vigor tests $\left(1^{\text {st }}\right.$ count, cold test and seedling emergence in the soil). Sterility, weight of a thousand seeds, seed yield and seed health, by the blotter test, were also evaluated. The results showed that fungicidal application in
\end{abstract}

${ }^{1}$ Submetido em 25/08/2009. Aceito para publicação em 04/11/2010. Parte da Dissertação de Mestrado do primeiro autor apresentada a UFPel.

${ }^{2}$ Alunos do Programa de Pós-Graduação em Ciência e Tecnologia de Sementes, FAEM, UFPel. E-mail: mteplizky@yahoo.com.br; fernandohenning@yahoo.com.br.
${ }^{3}$ Eng. Agr., D. Professor do Departamento de Fitotecnia FAEM, UFPEL. lobs@ufpel.edu.br.

${ }^{4}$ Eng. Agr., D. Empresa Agrícola PPC (Pesquisa, Planejamento e Consultoria) - Pelotas, RS, Brasil. 
irrigated rice improved yield and seed quality, regardless of the spray timing and hour of the day. A fungicide application at $1 \mathrm{pm}$ resulted in the lowest yield compare to the other application times. At high daylight temperatures and in more advanced stages of flowering, fungicide applications result in a lower seed quality.

Index terms: Oryza sativa, seed health, sterility, vigor.

\section{INTRODUÇÃO}

O arroz (Oryza sativa L.) é a base alimentar de grande parte da população e é um dos cereais mais cultivados no mundo. No Brasil, o arroz irrigado pode ser produzido em dezesseis estados brasileiros sob condições climáticas distintas, mas cerca de $60 \%$ da produção nacional é originária do Rio Grande do Sul (CONAB, 2009).

Apesar do crescente avanço do melhoramento genético na busca de materiais tolerantes às doenças, algumas delas ainda são fatores limitantes da produção e da qualidade de sementes. Conforme Ribeiro (1996) e Ribeiro e Sperandio (1998), entre todas as doenças que ocorrem em lavouras de arroz, a mais importante, devido ao prejuízo causado na produtividade, é a brusone (Pyricularia oryzae Cav.), com menor importância seguem-se a mancha parda (Drechslera oryzae Breda de Haan), escaldadura das folhas (Gerlachia oryzae (Hask \& Yok) W. Sams), mancha das glumas (Phoma sp., Phoma sorghina, Curvularia lunata, Nigrospora oryzae, Alternaria sp., Fusarium sp., e bactérias ); podridão do colmo (Sclerotium oryzae Catt.); queima das bainhas (Rhizoctonia solani Khun), mancha das bainhas (Rhizoctonia oryzae Riker \& Gooch) e a mancha estreita (Cercospora janseana).

Dentre essa elevada gama de fungos, alguns são saprófitas e outros até mesmo incapazes de ocasionar enfermidades na cultura, mas todos afetam de alguma forma a qualidade das sementes (Nakamura e Sader, 1986). O ataque de fungos pode acarretar em danos, que conseqüentemente ocasionam sementes manchadas, chochas, de menor peso ou com lesões necróticas. Conforme relata Yorinori (1982) e Schuch et al. (2006) a partir do ponto de maturidade fisiológica a presença de fitopatógenos pode ocasionar perdas de qualidade nas sementes. Quando as mesmas são contaminadas por agentes patogênicos podem ter elevado decréscimo em seu poder germinativo e problemas ligados ao vigor.

Com a dificuldade de incorporar em uma mesma cultivar tolerância a diversos patógenos, o controle químico destaca-se como ferramenta importante para garantir proteção às plantas e assegurar a qualidade das sementes. Segundo Sofiatti e Schuch (2005), a aplicação de fungicidas torna-se uma prática indispensável para produtores de sementes ou no cultivo em geral, para obtenção de um produto de maior qualidade e melhor padrão.

O fungicida tebuconazole pertence ao grupo de inibidores de biossíntese de esteróis, sendo o maior e mais importante grupo de compostos desenvolvidos para o controle de doenças fúngicas de plantas e animais, exibindo vários graus de sistemicidade $\mathrm{e}$, frequentemente, alta potência antifúngica (Andrei, 1997). A grande vantagem desse grupo de fungicidas sistêmicos é a dificuldade de os patógenos sensíveis tornarem-se resistentes.

As aplicações de agroquímicos sofrem grande influência das condições do ambiente. Os principais fatores são a temperatura e umidade relativa do ar, umidade do solo, velocidade do vento e a presença do orvalho. No sul do Brasil, normalmente a umidade relativa do ar é baixa nos meses de novembro a fevereiro entre as $10 \mathrm{~h}$ da manhã e às $18 \mathrm{~h}$ da tarde, ficando abaixo de $60 \%$ que é considerado o valor mínimo necessário para pulverização (Ruedell, 1995). Segundo Bonini (2003), pulverizações com fungicidas, principalmente, quando a temperatura for superior a $30^{\circ} \mathrm{C}$, podem causar efeitos prejudiciais à cultura.

Além dos fatores ambientais, o estádio de desenvolvimento da cultura também deve ser levado em consideração, pois conforme Prabhu et al. (1986) e Dallagnol et al. (2005), as doenças fúngicas afetam a área foliar das plantas, o que consequentemente afeta o processo de fotossíntese, incluindo a produção de fotoassimilados, o que pode acarretar em má formação das sementes.

Estudos conduzidos por Godoy e Canteri (2004), avaliando os efeitos de fungicidas no controle da ferrugem da soja [Glycine $\max$ (L.) Merrill], evidenciaram que o tratamento com tebuconazole proporcionou plantas menores e com folhas mais escuras, o que persistiu até 
o final do ensaio. Porém, em 2005, os mesmos autores verificaram que as parcelas tratadas com produtos contendo tebuconazole na formulação apresentaram leves sintomas de fitotoxicidade na área foliar, mas que não refletiram em perdas na produtividade.

Baseado no exposto objetivou-se neste trabalho avaliar o efeito da época e do horário de aplicação de fungicida, para o controle de doenças de final de ciclo, sobre o rendimento e a qualidade de sementes de arroz irrigado.

\section{MATERIAL E MÉTODOS}

O experimento foi conduzido no município de PelotasRS em solo classificado como Planossolo Hidromórfico Eutrófico Solódico. A adubação foi realizada conforme interpretação dos resultados da análise, sendo aplicados $300 \mathrm{~kg} \mathrm{ha}^{\mathrm{T}}$ da fórmula 4-17-27 $\left(\mathrm{N}-\mathrm{P}_{2} \mathrm{O}_{5}-\mathrm{K}_{2} \mathrm{O}\right)$.

Utilizou-se a cultivar "Combat" sendo a semeadura realizada em 23 de novembro de 2005, sobre solo com sistema de preparo convencional e uma densidade de semeadura de $150 \mathrm{~kg} \mathrm{ha}^{\mathrm{T}}$.

O delineamento experimental foi blocos ao acaso, com quatro repetições. As parcelas foram constituídas por 10 linhas de 5 metros de comprimento, espaçadas de 20 centímetros, totalizando $10 \mathrm{~m}^{2}$ de área útil. Testou-se uma combinação fatorial $(3 \times 3+1)$, sendo a aplicação do fungicida em três estádios de floração $(5 \%, 50 \%$ e $80 \%$ das plantas em floração) e em três horários de aplicação ( 9 horas, 13 horas e 17 horas), e um tratamento adicional sem fungicida (testemunha).

O fungicida utilizado nas aplicações foi o Folicur 200 CE $\square$ (tebuconazole $200 \mathrm{~g} \mathrm{~L}^{\mathrm{r}}$ ), na dosagem de $0,5 \mathrm{~L} \mathrm{ha}^{\mathrm{T}}$ do produto comercial.

A colheita das sementes foi realizada manualmente e a secagem realizada em silo secador estacionário, com temperatura do ar de secagem de $38{ }^{\circ} \mathrm{C}$, até atingirem $13 \%$ de umidade.

Teste de Germinação (TG) - realizado em germinador a $25{ }^{\circ} \mathrm{C}$ com quatro repetições de 100 sementes. As sementes foram distribuídas em rolo de papel toalha umedecido com água destilada, na proporção de 2,5 vezes o seu peso seco. As contagens de plântulas normais foram realizadas aos 5 e 10 dias após a instalação do teste (Brasil, 2009), sendo os resultados expressos em porcentagem.

Primeira Contagem de Germinação (PCG) porcentagem de plântulas normais contadas por ocasião da primeira contagem do teste de germinação.

Teste de Frio (TF) - realizado conforme Krzyzanowski et al. (1999), utilizando-se quatro repetições de 100 sementes. As sementes foram distribuídas em rolo de papel toalha umedecido com água destilada, na proporção de 2,5 vezes o seu peso seco. Os rolos foram colocados em geladeira a temperatura de $10{ }^{\circ} \mathrm{C}$ por sete dias. Após este período foram colocados no germinador à temperatura de $25 \pm 2{ }^{\circ} \mathrm{C}$. A contagem das plântulas normais foi realizada aos sete dias, sendo os resultados expressos em porcentagem.

Emergência em Solo (ES) - foi conduzido em campo, com quatro repetições de 400 sementes para cada tratamento. Cada parcela foi constituída por quatro linhas de 100 sementes. A semeadura foi realizada manualmente a profundidade de $2 \mathrm{~cm}$. A contagem de plântulas emergidas foi realizada aos 21 dias após a semeadura e os resultados expressos em porcentagem.

Porcentagem de Esterilidade (EST) - por ocasião da floração, após a aplicação dos tratamentos, foram marcadas 100 panículas por parcela. Na maturação essas panículas foram colhidas, trilhadas e utilizando um soprador mecânico, foram separadas as espiguetas vazias, as quais foram contadas. Após a determinação do número de espiguetas cheias, pela pesagem e o peso de 1000 sementes, foi determinada a porcentagem de esterilidade. Os resultados foram expressos em porcentagem.

Peso de mil sementes (PMS) - foram empregadas oito repetições de 100 sementes puras. Para estas pesagens calculou-se a média, o desvio padrão e o coeficiente de variação. Como para todas as parcelas o coeficiente de variação foi inferior a quatro, multiplicou-se a média por 10 , e assim obteve-se o peso de mil sementes, conforme a RAS (Brasil, 2009).

Rendimento (REND) - a partir da massa de grãos obtida na área útil da parcela obteve-se a produtividade, que foi expressa em kg.ha ${ }^{\mathrm{T}}$, corrigindo-se o peso para $13 \%$ de umidade, a qual foi obtida com o determinador de umidade universal. Utilizou-se a seguinte equação para correção da umidade de grãos: Rendimento $=$ Peso Bruto - [Peso Bruto x (\% umidade da amostra - 13) / 87].

Teste de Sanidade (TS) - foi utilizado o método do papel de filtro (Neergaard, 1979), com quatro repetições de quatro subamostras de 25 sementes. A avaliação foi realizada após o período de incubação, examinando-se individualmentetodas as sementes comauxíliodemicroscópio estereoscópico binocular com aumento de 6 a 50 vezes. Os resultados foram expressos em porcentagem. 
Delineamento Experimental - blocos ao acaso, em esquema fatorial de $3 \times 3+1$, com quatro repetições. Os dados obtidos foram submetidos à análise de variância. Com relação à comparação de médias, inicialmente utilizou-se uma primeira análise aplicando o teste de Dunnet a $5 \%$ de probabilidade, onde os diferentes tratamentos foram comparados contra a testemunha. Para comparar os efeitos de estádio de floração e horário de aplicação, as médias dos tratamentos onde houve a aplicação do fungicida foram submetidas ao teste de Duncan a $5 \%$ de significância. Para análise dos dados da análise sanitária utilizou-se a transformação arcsen $\sqrt{ }(\mathrm{x} / 100)$. A análise estatística foi realizada no programa computacional SAS (Sas Institute, 1989). Nas tabelas são apresentadas às médias originais.

\section{RESULTADOS E DISCUSSÃO}

De acordo com os resultados do teste de sanidade (Tabela 1), observou-se que a aplicação do fungicida reduziu a incidência total de fungos, independentemente do tratamento.

TABELA 1. Incidência de fungos por gênero (\%) e incidência total de fungos (ITF), avaliada pelo método do papel de filtro, em sementes de arroz irrigado, comparando-se a aplicação de fungicida em diferentes horários e estádios de floração com a testemunha sem aplicação, na safra 2005/2006.

\begin{tabular}{|c|c|c|c|c|c|c|c|}
\hline $\begin{array}{l}\text { Comparações } \\
\text { (Trat. vs test) }\end{array}$ & GER & PHO & CUR & FUS & DRE & ALT & ITF \\
\hline F1.H1 & $1 * *$ & $2 * *$ & $3 * *$ & $5 * *$ & $0 * *$ & $0 * *$ & $12 * *$ \\
\hline F1.H2 & $2 * *$ & $5 \mathrm{~ns}$ & $5 \mathrm{~ns}$ & $9 \mathrm{~ns}$ & $2 \mathrm{~ns}$ & $2 * *$ & $25 * *$ \\
\hline F1.H3 & $1 * *$ & $4 * *$ & $3 * *$ & $6 * *$ & $1 * *$ & $1 * *$ & $16^{* *}$ \\
\hline $\mathrm{F} 2 . \mathrm{H} 1$ & $1 * *$ & $2 * *$ & $3 * *$ & $6^{* *}$ & $0 * *$ & $0 * *$ & $12 * *$ \\
\hline $\mathrm{F} 2 . \mathrm{H} 2$ & $2 * *$ & $4 * *$ & $5 \mathrm{~ns}$ & $9 \mathrm{~ns}$ & $2 \mathrm{~ns}$ & $1 * *$ & $23 * *$ \\
\hline $\mathrm{F} 2 . \mathrm{H} 3$ & $2 * *$ & $2 * *$ & $3 * *$ & $6^{* *}$ & $1 * *$ & $1 * *$ & $16^{* *}$ \\
\hline F3.H1 & $1 * *$ & $2 * *$ & $4 \mathrm{~ns}$ & $6 * *$ & $0 * *$ & $1 * *$ & $14 * *$ \\
\hline $\mathrm{F} 3 . \mathrm{H} 2$ & $3 * *$ & $4 * *$ & $5 \mathrm{~ns}$ & $11 \mathrm{~ns}$ & $3 \mathrm{~ns}$ & $4 \mathrm{~ns}$ & $24 * *$ \\
\hline F3.H3 & $2 * *$ & $2 * *$ & $4 \mathrm{~ns}$ & $7 \mathrm{~ns}$ & $2 \mathrm{~ns}$ & $1 * *$ & $16^{* *}$ \\
\hline Testemunha & 21 & 8 & 6 & 11 & 4 & 7 & 57 \\
\hline
\end{tabular}

** Significativo aos $5 \%$ de probabilidade; ns = Não significativo

F1, F2 e F3 são os estádios de 5\%, 50\% e 80\% de floração, respectivamente.

H1, H2 e H3 são os horários de 9, 13 e 17 horas, respectivamente.

GER= Gerlachia spp.; PHO= Phoma spp.; CUR= Curvularia spp.; FUS= Fusarium spp.; DRE= Drechslera spp.; ALT= Alternaria spp.; ITF= Incidência Total de Fungos.

Considerando a ocorrência dos patógenos presentes no tratamento testemunha, destacaram-se fungos do gênero Gerlachia spp., seguidos pelos do gênero Fusarium spp. (Tabela1). Segundo Amaral et al. (1985), Brancão e Ribeiro (1993) e Schuch et al. (2006), o fungo Gerlachia spp., tem uma crescente incidência na região sul. Esse patógeno afeta principalmente a germinação de sementes de arroz, sendo o principal fitopatógeno responsável pela redução da qualidade fisiológica das sementes (Johansson, 1995, Sofiatti e Schuch (2005). Com relação aos fungos Fusarium spp, Phoma sp., Alternaria sp. e Curvularia sp (Tabela 1), embora considerados de importância secundária, causam manchas nas glumas das sementes de arroz o que afeta a germinação, a aparência visual e conseqüentemente o valor comercial dos lotes de sementes (Ribeiro e Tanaka, 1984; Ribeiro, 1988 e Motta Bicca 1998).

Para o fungo Drechslera oryzae, a aplicação de fungicida às 9 horas foi eficiente no controle deste patógeno para todos os estádios de floração avaliados. $\mathrm{O}$ 
tratamento sem aplicação de fungicida apresentou 4\% de incidência, não diferindo dos tratamentos com aplicação de fungicida às 13 horas, assim como naquela efetuada às 17 horas e estádio de $80 \%$ de floração, ressaltando que o fungicida utilizado é recomendado para o controle deste patógeno na cultura do arroz. Com isso, cuidados especiais, principalmente em relação ao horário de aplicação, devem ser tomados para controlar este fungo, pois na parte aérea o seu ataque pode acarretar grandes perdas, sendo relatadas reduções de $27 \%$ e $82 \%$ no número de sementes por panícula em cultivares de ciclo médio e longo, respectivamente (Pinto, 1989 e Coutinho et al. 2000).

Com relação aos dados da tabela 2 , observou-se que para o teste de germinação, teste de frio, emergência em solo e rendimento, os tratamentos com fungicida apresentaram desempenho superior à testemunha. Essa redução na germinação e no vigor das sementes oriundas do tratamento sem fungicida, é consequência da elevada incidência de fungos presentes nessas sementes (Tabela1), o que corrobora com os estudos de Ribeiro (1996); Lucca Filho (2001) e Pereira (2002). Com relação à esterilidade, para todos os tratamentos utilizados, não foi observada diferença significativa em relação à testemunha (Tabela 2), o que demonstra que independente do horário ou do estádio de floração, o fungicida não promoveu prejuízos à fertilidade. Nos testes de primeira contagem da germinação e peso de mil sementes, constatou-se que as aplicações realizadas no horário das 13 horas nos estádios de floração de 50\% e $80 \%$, foram as que apresentaram resultados inferiores não diferindo estatisticamente da testemunha (Tabela 2).

TABELA 2 .Valores médios de germinação, vigor (primeira contagem de germinação (PCG), teste de frio (TF) e emergência em solo (EME), esterilidade (EST), peso de mil sementes (PMS) e rendimento final (REND); comparando-se os tratamentos aonde houve aplicação de fungicida em diferentes horários e estádios de floração, com a testemunha sem aplicação, na safra 2005/2006.

\begin{tabular}{cccccccc}
\hline Comparações (Trat. Vs test) & PCG & TG & FRIO & EME & EST & PMS & REND \\
\hline F1.H1 & $86^{* *}$ & $93^{* *}$ & $88^{* *}$ & $85^{* *}$ & $2.0 \mathrm{~ns}$ & $27.6^{* *}$ & $6734^{* *}$ \\
F1.H2 & $85^{* *}$ & $94 * *$ & $88^{* *}$ & $85^{* *}$ & $4.0 \mathrm{~ns}$ & $27.4^{* *}$ & $6574 * *$ \\
F1.H3 & $86^{* *}$ & $94 * *$ & $89 * *$ & $86^{* *}$ & $2.5 \mathrm{~ns}$ & $27.2^{* *}$ & $6730^{* *}$ \\
F2.H1 & $84^{* *}$ & $94 * *$ & $87^{* *}$ & $86^{* *}$ & $2.5 \mathrm{~ns}$ & $27.5^{* *}$ & $6722^{* *}$ \\
F2.H2 & $80 \mathrm{~ns}$ & $93 * *$ & $84^{* *}$ & $82^{* *}$ & $4.5 \mathrm{~ns}$ & $26.1 \mathrm{~ns}$ & $6574 * *$ \\
F2.H3 & $84^{* *}$ & $94 * *$ & $89 * *$ & $86^{* *}$ & $4.0 \mathrm{~ns}$ & $27.5^{* *}$ & $6711^{* *}$ \\
F3.H1 & $84^{* *}$ & $94 * *$ & $85^{* *}$ & $82^{* *}$ & $2.5 \mathrm{~ns}$ & $26.4^{* *}$ & $6700^{* *}$ \\
F3.H2 & $80 \mathrm{~ns}$ & $92 * *$ & $86^{* *}$ & $80^{* *}$ & $4.0 \mathrm{~ns}$ & $25.7 \mathrm{~ns}$ & $6522^{* *}$ \\
F3.H3 & $84^{* *}$ & $93 * *$ & $88^{* *}$ & $82^{* *}$ & $3.0 \mathrm{~ns}$ & $26.5 * *$ & $6711^{* *}$ \\
\hline Testemunha & 78 & 89 & 83 & 76 & 3 & 25 & 5449 \\
\hline
\end{tabular}

** Significativo aos $5 \%$ de probabilidade; ns = Não significativo

F1, F2 e F3 são os estádios de 5\%, 50\% e $80 \%$ de floração, respectivamente.

H1, H2 e H3 são os horários de 9, 13 e 17 horas, respectivamente.

A análise de variância dos dados arranjados em esquema fatorial revelou efeito significativo da interação entre estádio de floração e horário de aplicação para as seguintes variáveis: germinação, primeira contagem da germinação, teste de frio, emergência em solo, peso de mil sementes e para os fungos Fusarium spp. e Alternaria spp.

Nas tabelas 3 e 4 realizou-se uma análise através do teste de Duncan, onde foram comparados os estádios de floração e horários de aplicação do fungicida. Com relação à análise sanitária (Tabela 3), para todos os patógenos avaliados o horário de aplicação das 13 horas foi o que apresentou maior incidência de fungos, com exceção de Gerlachia spp. Este fato foi salientado por Matuo (1990) e por Hoffmann e Boller (2004), os quais relatam que aplicações próximas às 13 horas são menos eficientes no controle fúngico, devido a menor 
absorção de fungicida pelas plantas e maiores perdas do produto por volatilização e deriva, como consequência das condições ambientais menos favoráveis. Quanto ao fungo Drechslera spp., (Tabela 3), para todos os estádios de floração a aplicação de fungicida às 9 horas eliminou completamente a presença desse fungo nas sementes.

TABELA 3. Incidência de fungos e incidência total de fungos (ITF) em sementes de arroz irrigado, em função de aplicação de fungicida em diferentes horários e estádios de floração na safra 2005/2006.

\begin{tabular}{|c|c|c|c|}
\hline \multirow{2}{*}{ Época Floração } & \multicolumn{3}{|c|}{ Horários de Aplicação } \\
\hline & $\mathrm{H} 1$ & $\mathrm{H} 2$ & $\mathrm{H} 3$ \\
\hline \multicolumn{4}{|l|}{ Gerlachia spp. } \\
\hline $\mathrm{F} 1$ & $1 \mathrm{Aa}$ & $2 \mathrm{Aa}$ & $1 \mathrm{Aa}$ \\
\hline $\mathrm{F} 2$ & $1 \mathrm{Aa}$ & $2 \mathrm{Aa}$ & $2 \mathrm{Aa}$ \\
\hline $\mathrm{F} 3$ & $1 \mathrm{Aa}$ & $3 \mathrm{Aa}$ & $2 \mathrm{Aa}$ \\
\hline \multicolumn{4}{|l|}{ Phoma spp. } \\
\hline $\mathrm{F} 1$ & $2 \mathrm{Ab}$ & $5 \mathrm{Aa}$ & $4 \mathrm{Aa}$ \\
\hline $\mathrm{F} 2$ & $2 \mathrm{Aa}$ & $4 \mathrm{Aa}$ & $2 \mathrm{Aa}$ \\
\hline $\mathrm{F} 3$ & $2 \mathrm{Aa}$ & $4 \mathrm{Aa}$ & $2 \mathrm{Aa}$ \\
\hline \multicolumn{4}{|l|}{ Curvularia spp. } \\
\hline $\mathrm{F} 1$ & $3 \mathrm{Ab}$ & $5 \mathrm{Aa}$ & $3 \mathrm{Ab}$ \\
\hline $\mathrm{F} 2$ & $3 \mathrm{Ab}$ & $5 \mathrm{Aa}$ & $3 \mathrm{Ab}$ \\
\hline F3 & $4 \mathrm{Ab}$ & $5 \mathrm{Aa}$ & $4 \mathrm{Ab}$ \\
\hline \multicolumn{4}{|l|}{ Fusarium spp. } \\
\hline $\mathrm{F} 1$ & $5 \mathrm{Ab}$ & $9 \mathrm{Aa}$ & $6 \mathrm{Ab}$ \\
\hline $\mathrm{F} 2$ & $6 \mathrm{Ab}$ & $9 \mathrm{Aa}$ & $6 \mathrm{Ab}$ \\
\hline F3 & $6 \mathrm{Ab}$ & $11 \mathrm{Ba}$ & $7 \mathrm{Ab}$ \\
\hline \multicolumn{4}{|l|}{ Drechslera spp. } \\
\hline $\mathrm{F} 1$ & $0 \mathrm{Aa}$ & $2 \mathrm{Aa}$ & $1 \mathrm{Aa}$ \\
\hline $\mathrm{F} 2$ & $0 \mathrm{Aa}$ & $2 \mathrm{Aa}$ & $1 \mathrm{Aa}$ \\
\hline $\mathrm{F} 3$ & $0 \mathrm{Ab}$ & $3 \mathrm{Aa}$ & $2 \mathrm{Aa}$ \\
\hline \multicolumn{4}{|l|}{ Alternaria spp. } \\
\hline $\mathrm{F} 1$ & $0 \mathrm{Aa}$ & $2 \mathrm{Aa}$ & $1 \mathrm{Aa}$ \\
\hline $\mathrm{F} 2$ & $0 \mathrm{Aa}$ & $1 \mathrm{Aa}$ & $1 \mathrm{Aa}$ \\
\hline $\mathrm{F} 3$ & $1 \mathrm{Ab}$ & $4 \mathrm{Ba}$ & $1 \mathrm{Ab}$ \\
\hline \multicolumn{4}{|l|}{ ITF } \\
\hline $\mathrm{F} 1$ & $12 \mathrm{Ac}$ & $25 \mathrm{Aa}$ & $16 \mathrm{Ab}$ \\
\hline $\mathrm{F} 2$ & $12 \mathrm{Ac}$ & $23 \mathrm{Aa}$ & $16 \mathrm{Ab}$ \\
\hline F3 & $14 \mathrm{Ab}$ & $24 \mathrm{Aa}$ & $16 \mathrm{Ab}$ \\
\hline
\end{tabular}

*Médias seguidas pela mesma letra maiúscula (Estádios de floração) na vertical para cada variável e minúscula (Horário de aplicação) na horizontal não diferem entre si pelo teste de Duncan, a $5 \%$ de probabilidade.

F1, F2 e F3 são os estádios de 5\%, 50\% e $80 \%$ de floração, respectivamente.

H1, H2 e H3 são os horários de 9, 13 e 17 horas, respectivamente.

Para as variáveis de qualidade fisiológica de sementes (germinação, primeira contagem, teste de frio, emergência em solo e peso de mil sementes), de acordo com os dados da tabela 4 observou-se que, de maneira geral, o horário 
de aplicação das 13 horas, o qual coincide com horários mais quentes do dia, nas épocas de 50 e $80 \%$ de floração, foram os que apresentaram os menores resultados. Isto pode ter ocorrido devido à falta de eficiência destes tratamentos no controle de fungos. De acordo com Ribeiro e Sperandio (1998) estes patógenos podem prejudicar o desenvolvimento e enchimento das sementes. Já com relação à esterilidade de espiguetas, independente do horário ou da época de aplicação do produto, não se observou diferença significativa. Com relação aos dados de rendimento, observou-se efeito apenas do horário (Tabela 4), demonstrando novamente que as aplicações de fungicida no horário das 13 horas resultaram em menor rendimento de sementes do que nos tratamentos das 9 e 17 horas, confirmando que esse horário foi o menos indicado para aplicação do produto.

TABELA 4. Valores médios de germinação, vigor (primeira contagem de germinação, teste de frio e emergência em solo), esterilidade, peso de mil sementes e rendimento final; comparando-se os tratamentos aonde houve aplicação de fungicida em diferentes horários e estádios de floração, na safra 2005/2006.

\begin{tabular}{|c|c|c|c|}
\hline \multirow{2}{*}{ Época Floração } & \multicolumn{3}{|c|}{ Horários de aplicação } \\
\hline & H1 & $\mathrm{H} 2$ & $\mathrm{H} 3$ \\
\hline \multicolumn{4}{|l|}{ Germinação } \\
\hline $\mathrm{F} 1$ & $93 \mathrm{Aa}$ & $94 \mathrm{Aa}$ & $94 \mathrm{Aa}$ \\
\hline $\mathrm{F} 2$ & $94 \mathrm{Aa}$ & $93 \mathrm{Aa}$ & $94 \mathrm{Aa}$ \\
\hline $\mathrm{F} 3$ & $94 \mathrm{Aa}$ & $92 \mathrm{Bb}$ & $93 \mathrm{Aa}$ \\
\hline \multicolumn{4}{|c|}{ Primeira contagem } \\
\hline $\mathrm{F} 1$ & $86 \mathrm{Aa}$ & $85 \mathrm{Aa}$ & $86 \mathrm{Aa}$ \\
\hline $\mathrm{F} 2$ & $84 \mathrm{Ba}$ & $80 \mathrm{Bb}$ & $84 \mathrm{Ba}$ \\
\hline F3 & $84 \mathrm{Ba}$ & $80 \mathrm{Bb}$ & $84 \mathrm{Ba}$ \\
\hline \multicolumn{4}{|l|}{ Frio } \\
\hline F1 & $88 \mathrm{Aa}$ & $88 \mathrm{Aa}$ & $89 \mathrm{Aa}$ \\
\hline $\mathrm{F} 2$ & $87 \mathrm{Ab}$ & $84 \mathrm{Cc}$ & $89 \mathrm{Aa}$ \\
\hline F3 & $85 \mathrm{Bb}$ & $86 \mathrm{Bb}$ & $86 \mathrm{Aa}$ \\
\hline \multicolumn{4}{|c|}{ Emergência em solo } \\
\hline $\mathrm{F} 1$ & $85 \mathrm{Aa}$ & $85 \mathrm{Aa}$ & $86 \mathrm{Aa}$ \\
\hline $\mathrm{F} 2$ & $86 \mathrm{Aa}$ & $85 \mathrm{Aa}$ & $86 \mathrm{Aa}$ \\
\hline F3 & $82 \mathrm{Ba}$ & $80 \mathrm{Bb}$ & $82 \mathrm{Ba}$ \\
\hline \multicolumn{4}{|l|}{ Esterilidade } \\
\hline $\mathrm{F} 1$ & $2 \mathrm{Aa}$ & $4 \mathrm{Aa}$ & $2.5 \mathrm{Aa}$ \\
\hline $\mathrm{F} 2$ & $2.5 \mathrm{Aa}$ & 4.5 Aa & $4 \mathrm{Aa}$ \\
\hline F3 & $2.5 \mathrm{Aa}$ & $4 \mathrm{Aa}$ & $3 \mathrm{Aa}$ \\
\hline \multicolumn{4}{|l|}{ Peso de mil } \\
\hline $\mathrm{F} 1$ & $27.6 \mathrm{Aa}$ & $27.4 \mathrm{Aa}$ & $27.2 \mathrm{Aa}$ \\
\hline $\mathrm{F} 2$ & $27.5 \mathrm{Aa}$ & $26.1 \mathrm{Ab}$ & $27.5 \mathrm{Aa}$ \\
\hline F3 & $26.4 \mathrm{Aa}$ & $25.7 \mathrm{Bb}$ & $26.5 \mathrm{Aa}$ \\
\hline \multicolumn{4}{|l|}{ Rendimento } \\
\hline $\mathrm{F} 1$ & $6734 \mathrm{Aa}$ & $6574 \mathrm{Ab}$ & $6730 \mathrm{Aa}$ \\
\hline $\mathrm{F} 2$ & $6722 \mathrm{Aa}$ & $6574 \mathrm{Ab}$ & $6711 \mathrm{Aa}$ \\
\hline F3 & $6700 \mathrm{Aa}$ & $6522 \mathrm{Ab}$ & $6711 \mathrm{Aa}$ \\
\hline
\end{tabular}

*Médias seguidas pela mesma letra maiúscula (Estádios de floração) na vertical para cada variável e minúscula (Horário de aplicação) na horizontal não diferem entre si pelo teste de Duncan, a $5 \%$ de probabilidade.

F1, F2 e F3 são os estádios de 5\%, 50\% e $80 \%$ de floração, respectivamente.

H1, H2 e H3 são os horários de 9, 13 e 17 horas, respectivamente. 


\section{CONCLUSÕES}

A aplicação de fungicida na cultura do arroz resulta em maior rendimento e melhor qualidade de sementes, independente do horário e da época de aplicação do produto.

A aplicação de fungicida no horário das 13 horas apresenta menor rendimento de grãos em relação aos demais horários de aplicação, independente do estádio de floração.

Em horário com temperaturas elevadas e em estádios de floração mais avançados, a aplicação de fungicida resulta em sementes de menor qualidade.

\section{REFERÊNCIAS}

AMARAL, H.M.; RIBEIRO, A.S.; LUCCA FILHO, O.A. Diagnóstico da patologia de sementes de arroz no Brasil. Revista Brasileira de Sementes, v.7, n.1, p.183-187, 1985.

ANDREI, E. (Coord). Compêndio de defensivos agrícolas. São Paulo, v.6, 1997. 458p.

BONINI, J.V. Tecnologia de aplicação de fungicidas na cultura da soja, 2003. 82f. Dissertação (Mestrado em Agronomia - UFSM). Universidade Federal de Santa Maria, Santa Maria, 2003.

BRANCÃO, N.; RIBEIRO, A.S. Fungos em sementes de soja, arroz e sorgo em terras baixas da região Sul do Rio Grande do Sul. Fitopatologia Brasileira, v.18, p.284-285, 1993.

BRASIL. Ministério da Agricultura, Pecuária e Abastecimento. Regras para análise de sementes. Ministério da Agricultura, Pecuária e Abastecimento. Secretaria de Defesa Agropecuária. Brasília, DF: Mapa/ ACS, 2009. 395p.

COMPANHIA NACIONAL DE ABASTECIMENTO. CONAB- 2009. Disponivel em: <http:/ www.conab.gov. br> Acesso em: 1 jul. 2009.

COUTINHO, W.M.; PEREIRA, L.A.A.; MACHADO, J. da C.; MAGALHÃES, F.H.L.; PENA, R.C.M.; VIEIRA, M.G.G.C. Qualidade fisiológica de sementes de arroz em função da ocorrência diferenciada de Drechelera oryzae. Ciência e Agrotecnologia, v.24, n.1, p.124-129, 2000.

DALLAGNOL, L.J.; BALARDIN, R.S.; MADALOSSO, M. Efeito do controle químico das doenças foliares sobre a produção e qualidade de arroz. In: CONGRESSO BRASILEIRO DE ARROZ IRRIGADO, 4., 2005, Santa
Maria - RS, Anais... Santa Maria: UFSM, 2005. p.511513.

GODOY, C.V.; CANTERI, M.G. Efeitos protetor, curativo e erradicante de fungicidas no controle da ferrugem da soja causada por Phakopsora pachyrhizi, em casa de vegetação. Fitopatologia Brasileira, v.29, n.1, p.97-101, 2004.

HOFFMANN, L.L.; BOLLER, W. Tecnologia de aplicação de fungicidas em soja. In: REIS, E.M. Doenças na cultura da soja. Aldeia Norte Editora, Passo Fundo, p.147-170, 2004.

JOHANSSON, M. Pathogenic fungi in rice seed. a minor field study. Swedish: International Rural Development Centre/Swedish University of Agricultural Sciences, 1995.

KRZYZANOWSKI, F.C.; VIEIRA, R.D.; FRANÇA NETO, J.B. Vigor de sementes: conceitos e testes. Associação Brasileira de Tecnologia de Sementes, Comitê de vigor de sementes, ABRATES, Londrina, 1999. 218p.

LUCCA FILHO, O.A. Patologia de sementes. Brasília, DF: ABEAS, 2001. 54p. (ABEAS. Curso de especialização por tutoria à distância. ABEAS/ UFPel/ FAEM).

MATUO, T. Técnicas de aplicação de defensivos. Funep, Jaboticabal, 1990. 139p.

MOTTA BICCA, F.; BAUDET, L.; ZIMMER, G.J. Separação de sementes manchadas de lotes de sementes de arroz, utilizando a mesa de gravidade e sua influência na qualidade sanitária. Revista Brasileira de Sementes, v.20, n.1, p.106-111, 1998.

NAKAMURA, A.M.; SADER, R. Efeito da infecção por fungos na germinação e vigor de sementes de arroz. Revista Brasileira de Sementes, v.8, n.1, p.101-111, 1986.

NEERGAARD, P. Seed Pathology. London, Macmillan Press, 1979. 839p.

PEREIRA, J.L. de A. Patologia de sementes de arroz, 2002.

PINTO, H.M. do A. Drechslera oryzae (Breda de Hann) Subram \& Jain em sementes de arroz (Oryza sativa L.) quantificação e localização do inóculo, efeitos no estabelecimento da cultura e controle com fungicidas. 1989. 85f. Dissertação (Mestrado em Agronomia/ Fitopatologia). ESALQ, Piracicaba, 1989.

PRABHU, A.S.; FARIA, J.C.; CARVALHO, J.R.P. Efeito da brusone sobre a matéria seca, produção de grãos e seus componentes em arroz de sequeiro. Pesquisa Agropecuária Brasileira, v.21, n.5, p.495-500, 1986.

RIBEIRO, A.S.; TANAKA, M.A.S. Doenças do arroz e 
medida de controle. Informe Agropecuário, v.10, n.14, p.24-32, 1984.

RIBEIRO, A.S. Doenças do arroz irrigado. Pelotas: EMBRAPA - CPATB, 1988. 56p. (Circular Técnica, 18).

RIBEIRO, A.S. Tratamento de sementes com fungicidas. Revisão Anual de Patologia de Plantas, v.4, p.381-409, 1996.

RIBEIRO, A.S.; SPERANDIO, C.A. Controle de doenças na cultura do arroz irrigado. In: PESKE, S.T.; NEDEL, J.L.; BARROS, A.C.S.A. Produção de arroz irrigado. Pelotas: Universidade Federal de Pelotas, 1998. p.301-349.

RUEDELL, J. Plantio Direto na Região de Cruz Alta. Convênio FUNDACEP/BASF. FUNDACEP FECOTRIGO, Cruz Alta, RS, 1995. 134p.
SAS. SAS/STAT User's guide. Version 6, 4.ed. SAS Cary, NC, Institute Inc, 1989.

SCHUCH, J.Z.; LUCCA FILHO, O.A.; PESKE, S.T.; DUTRA, L.M.C.; BRANCÃO, M.F.; ROSENTHAL, M.A. Qualidade fisiológica e sanitária de sementes de arroz com diferentes graus de umidade e tratadas com fungicida. Revista Brasileira de Sementes, v.28, n.1, p.45-53, 2006.

SOFIATTI, V.; SCHUCH, L.O.B. Efeito de regulador de crescimento e controle químico de doenças na qualidade fisiológica e sanitária de sementes de arroz. Revista Brasileira de Sementes, v.27, n.2, p.102-110, 2005.

YORINORI, J.C. Doenças de soja causadas por fungos. Informe Agropecuário, v.8, n.9, p.40-46, 1982. 